University of Wollongong

Research Online

Faculty of Arts, Social Sciences and Humanities

- Papers

Faculty of Arts, Social Sciences \& Humanities

2020

Effects of different types of classroom physical activity breaks on children's on-task behaviour, academic achievement and cognition

Myrto F. Mavilidi

University of Wollongong, myrto@uow.edu.au

Ryan Drew

University Of Newcastle

Philip J. Morgan

University Of Newcastle, Philip.Morgan@newcastle.edu.au

David R. Lubans

University Of Newcastle, david.lubans@newcastle.edu.au

Mirko Schmidt

University of Bern

See next page for additional authors

Follow this and additional works at: https://ro.uow.edu.au/asshpapers

Research Online is the open access institutional repository for the University of Wollongong. For further information contact the UOW Library: research-pubs@uow.edu.au 


\title{
Effects of different types of classroom physical activity breaks on children's on- task behaviour, academic achievement and cognition
}

\author{
Abstract \\ Aim \\ This study examined the effects of different types of classroom physical activity breaks on children's on- \\ task behaviour, academic achievement and cognition.
}

\section{Methods}

Participants were 87 Australian primary school students (mean age $9.11 \pm 0.62$ years), recruited from one school. Three classes were randomly assigned either to activity breaks only $(n=29)$, activity breaks and mathematics combined $(n=29)$, or control conditions involving only mathematical content $(n=29)$. Students were engaged in five minutes of classroom physical activity breaks, three times per week, for four weeks (divided into two minutes at the beginning of the usual mathematics curriculum lesson and three minutes in the middle of the lesson). Assessments were conducted at baseline and post-test.

\section{Results}

Significant group-by-time effects were found for on-task behaviour (active engagement: activity breaks and mathematics combined versus control, $p \leq 0.001$; activity breaks versus control, $p \leq 0.001$; activity breaks and mathematics combined versus activity breaks, $p=0.037$; passive engagement: activity breaks and mathematics combined versus control, $p \leq 0.001$ ) and mathematics scores (activity breaks versus control, $p=0.045)$.

\section{Conclusion}

Physical activity breaks with and without integrated mathematics content were effective in improving children's on-task behaviour and learning scores.

\section{Keywords}

achievement, academic, behaviour, on-task, children's, cognition, breaks, effects, activity, physical, classroom, types, different

\section{Publication Details}

Mavilidi, M. F., Drew, R., Morgan, P. J., Lubans, D. R., Schmidt, M. \& Riley, N. (2020). Effects of different types of classroom physical activity breaks on children's on-task behaviour, academic achievement and cognition. Acta Paediatrica, 109 (1), 158-165.

\section{Authors}

Myrto F. Mavilidi, Ryan Drew, Philip J. Morgan, David R. Lubans, Mirko Schmidt, and Nick Riley 
Effects of different types of classroom physical activity breaks on children's on-task behaviour and academic achievement, and cognition.

Myrto F. Mavilidi ${ }^{1}$, Ryan Drew ${ }^{1}$, Philip J. Morgan ${ }^{1}$, David R. Lubans ${ }^{1}$, Mirko Schmidt ${ }^{2}$, and Nicholas Riley ${ }^{1}$

${ }^{1}$ Priority Research Centre for Physical Activity and Nutrition, School of Education, University of Newcastle, Australia

${ }^{2}$ Institute of Sport Science, University of Bern, Bern, Switzerland

Author Note

Myrto-Foteini Mavilidi, Priority Research Centre for Physical Activity and Nutrition,

School of Education, University of Newcastle, NSW 2308, Australia, Email:

Myrto.Mavilidi@newcastle.edu.au, Phone No: +61249216242

Short title: Classroom physical activity breaks 


\begin{abstract}
Aim: This study examined the effects of different types of classroom physical activity breaks on children's on-task behaviour, academic achievement and cognition.

Methods: Participants were 87 Australian primary school students (mean age $9.11 \pm$ 0.62 years), recruited from one school. Three classes were randomly assigned either to activity breaks only $(n=29)$, activity breaks and mathematics combined $(n=29)$, or control conditions involving only mathematical content $(n=29)$. Students were engaged in five minutes of classroom physical activity breaks, three times per week, for four weeks (divided into two minutes at the beginning of the usual mathematics curriculum lesson, and three minutes in the middle of the lesson). Assessments were conducted at baseline and post-test.
\end{abstract}

Results: Significant group-by-time effects were found for on-task behaviour (active engagement: activity breaks and mathematics combined versus control, $p \leq 0.001$; activity breaks versus control, $p \leq 0.001$; activity breaks and mathematics combined versus activity breaks, $p=0.037$; passive engagement: activity breaks and mathematics combined versus control, $p \leq 0.001$ ), and mathematics scores (activity breaks versus control, $p=0.045$ ).

Conclusion: Physical activity breaks with and without integrated mathematics content were effective in improving children's on-task behaviour and learning scores.

Keywords: Academic achievement, cognition, on-task behaviour, physical activity breaks, primary school children

\title{
Key notes:
}

- Low levels of physical activity are associated with poor cognitive and mental health in children.

- Participation in classroom physical activity breaks may enhance children's on-task behaviour and academic achievement. 
- Additional studies in diverse populations are needed to replicate these preliminary positive findings.

\section{Funding}

This study was funded by the NSW Department of Education, Department of Education (New South Wales, Australia), Premier's Sporting Challenge, as part of the School Sport Unit's program to support teacher professional development.

\section{Conflict of interest}

The authors have no conflicts of interest to declare.

\section{Complete list of abbreviations}

- NSW: New South Wales

- IBFA: Individual Basic Facts Assessment Tool

- PISA: Program for International Student Assessment

- ACER: Australian Council for Educational Research

- $\mathrm{Cl}$ : Confidence Intervals

- $\mathrm{AB}$ : Activity breaks

- ABM: Activity breaks and mathematics combined 


\section{INTRODUCTION}

Regular participation in physical activity is essential for children's healthy growth and development. The physiological health benefits are extensive and include improved physical fitness and bone health, reduced obesity, type II diabetes, high blood pressure, or cardiovascular disease (1). Additionally, there are a number of psychological benefits including psychological well-being such as improvements in self-confidence and self-esteem, reduced levels of stress, anxiety and depression(2). Emerging research has also demonstrated benefits of physical activity on children's cognition, meta-cognition, student engagement and academic performance(3). Despite these benefits, global estimates indicate that fewer than $19 \%$ of young people are achieving the recommended guidelines of 60 minutes per day of moderate-to-vigorous physical activity(4).

A systematic review and meta-analysis suggested that successful intervention programs that increase physical activity during the school day include physically active academic lessons, physically active classroom breaks, and curriculum-focused physical activity breaks(5). Curriculum-focused physical activity breaks contain short bouts of physical activity but also include curriculum content(6). For instance, the Take 10 program included ten minutes of classroom-based physical activity breaks, allowing students to move around during academic instruction for 12 weeks(6). An example of physical activities used was to read aloud texts containing action verbs, while students were required to act according to the meaning of these verbs such as for example, dive, jump, or walk. Higher physical activity levels and improved on-task behaviour were shown in the intervention compared to the sedentary control group.

Empirical studies on acute physical activity breaks lasting ten minutes found positive selective effects on children's cognitive functions(7). The quantitative characteristics of physical activity such as for example, type, amount, frequency, and duration and their association with cognitive and academic performance still remain to be explored(3). Therefore, the aim of the current study was to examine the relative impact of activity breaks 
and activity breaks and mathematics combined compared to a traditional sedentary control group on on-task behaviour, cognitive outcomes, and academic achievement in primary school students. We hypothesised that students randomised to both the activity breaks and activity breaks and mathematics combined groups would demonstrate greater improvements in on-task behaviour, cognition, academic achievement and attitudes towards mathematics compared to students in the control group. We also hypothesised that improvements in the activity breaks and mathematics combined group would be larger than those observed in the activity breaks group.

\section{METHODS}

\section{Design}

Study approval for this group randomised controlled trial was obtained from the University of Newcastle Human Research Ethics Committee (No: H-2010-1183), and the New South Wales (NSW) Department of Education (SERAP No: 2017-359). A mixed $3 \times 2$ between-subjects experimental design, compared the experimental conditions (activity breaks and mathematics combined, activity breaks, control), measured in two time points (baseline and post-test).

\section{Participants}

One primary school located in Newcastle, NSW Australia was recruited to participated in this study. The school principal, teachers and parents were provided with information statements. All students received the program as a whole-class intervention. However, data was recorded only for those who returned their written consent forms (consent rate was 96.6\%). Following baseline assessments, classes were randomly assigned to one of three experimental conditions: activity breaks $(n=29)$, activity breaks and mathematics combined ( $n=29)$, and control condition ( $n=29 ;$ Figure 1). In total, 87 students (53 males) participated with a mean age $9.11 \pm 0.62$ years. Participants' demographics are presented in Table 1 . The majority of the participants identified as having an Australian cultural background (97.7\%), and having English as the spoken language at home (98.9\%). This study was 
designed as a pilot study to assist in the design of a larger-scale cluster randomised controlled trial. According to Eldridge and colleagues, a priori power calculations are not necessary for pilot studies(8).

\section{Procedure}

This intervention involved two different types of activity breaks delivered in separate classes, both totalling five minutes. The classroom environment of the three classes was similar in regards to teacher experience, class size and set up. The activity breaks were delivered three times per week, every Monday, Wednesday and Friday, for four weeks. The activity breaks were divided into two minutes of activity break at the beginning of the lesson and three minutes in the middle of the lesson. This specific experimental design was considered to be feasible and acceptable for teachers in the classroom: the focus was placed on moderate to vigorous physical activity, at both times (two-minute breaks in the beginning and three-minute breaks during the lesson), as well as interrupting prolonged periods of sedentary behaviour during the middle of the mathematics lessons (three-minute break). The remaining lessons consisted of the usual mathematics program. The activity breaks were performed in the classroom during the usual scheduled morning mathematics lessons $(9.30$ am - $11.00 \mathrm{am})$. To ensure consistency among the experimental conditions and avoid teacher biases during implementation and administering of the intervention, the physical activities were projected in short pre-recorded videos prepared by the research team (Figure 2). The same two instructors demonstrated the activities in the videos. The videos were consisting of 40 or 60 short mathematical questions, and six or nine physical activities for the two and three minutes accordingly.

Both the two physical activity conditions, activity breaks and activity breaks and mathematics combined conditions, consisted of exactly the same movements categorised into three themes related to physical activity: combat (e.g., straight and cross-over punches, squats), fitness (e.g., skipping, jumping jacks, jogging on the spot), and cardio (e.g., lunges, skater jumps, push ups). The activities were designed in consideration of the youth compendium of physical activities, which classifies active classroom breaks as moderate 
intensity $(\sim 4 \mathrm{METs})(9)$. Before commending the trial, the activities were piloted with children and their level of exertion was observed.

The content of the mathematical concepts during the intervention and assessments was relevant to basic maths skills (e.g., multiplication, division, counting forwards, backwards) that students are expected to have acquired at this age group. However, it was independent from the syllabus taught by the teachers. During the intervention, each question was shown for five seconds and then feedback with the correct answer was provided before the appearance of the following question.

Each class was randomly assigned into a different experimental condition: The control condition included mathematical activities such as multiplication tables, counting forwards, backwards (same mathematical activities as in the activity breaks and mathematics condition). The activity breaks condition included aerobic activities such as squats, straight or crossover punches, lunges, star jumps, running on the spot. Children were asked to copy the movements. Finally, the activity breaks and mathematics combined condition included the same mathematical activities embedded into the same aerobic activities as the other conditions. Children were asked to copy the movements and additionally answer the mathematical questions while moving.

Baseline data was collected in the week before the beginning of the intervention. Each class was first observed during their mathematics lessons (baseline measure of on-task behaviour), and then children were assessed on their mathematical knowledge (with standardised academic achievement tests). The first part of the mathematical assessment included mathematical questions, while the second part consisted of questions related to children's attitudes towards mathematics. Children were assessed as a group. The second day included individual cognitive assessments. The third day, the intervention program was initiated, involving classroom short activity breaks.

At the end of the intervention, identical procedures and materials with baseline were utilised for the post-test measures, starting with the on-task behaviour, academic achievement, and 
finally cognitive assessments. More specifically, on-task behaviour measures in the post-test incorporated the observation of students in the class while having the two-minute and threeminute breaks. All the assessments were conducted during normal class time by trained members of the research team not blinded to the experimental conditions. Teachers reported that they delivered all five-minute sessions per week over the four weeks.

\section{Measures}

On-task behaviour was observed using momentary time sampling(10) and was reported as a percentage of time on-task (consisted of active engagement or passive engagement), and time off-task. This observational tool was adapted from the Behaviour observation of students in schools(10) and the Applied behaviour analysis for teachers(11). On-task behaviour includes behaviour that can be categorised as being 'actively engaged' in academic responding such as reading, writing, performing as set task, or 'passively engaged' including listening to a teacher or a fellow student, but not actively participating in the set task. Off-task behaviour includes behaviour that can be described as either off-task motor, where a child has moved in a manner not associated with the task such as walking around the class, off-task verbal, when a child is involved in irrelevant verbal discussion, or off-task passive when a child is non-engaged and "staring into space" $(6,12)$.

Using a random number-producing algorithm, 12 students per class (6 males, 6 females) were randomly selected and matched against the alphabetical roll. All students were observed by members of the research team in 15-second intervals on a rotational basis over a 30-minute period in the allocated maths time slot (9.30 am - $11.00 \mathrm{am})$. At each time point, baseline and post-test, 12 observations per class were included. A two-hour training session was conducted on the university campus before the start of the intervention. During this training, observers focused on identifying and classifying behaviour into the appropriate categories, and a practice trial was conducted using a university class. Following all observations in the practice trial, the observers discussed the different categories and compared notes to clarify discrepancies. During the actual study period, students were aware of the presence of the research team in the class, without knowing the actual purpose of their 
visit. Observers were standing at the back of the classroom so that students did not have a direct eye contact with them. We did not establish an interrater reliability for this study. However, our research team previously established an intraclass correlation coefficient of 0.84 for the same on-task behaviour assessments in preparation for another study.

Academic achievement: Students' mastery of basic facts was assessed using the Stage 2 version of the Individual Basic Facts Assessment Tool (IBFA(13)). Questions were projected on a computer screen and were accessible to all students, while they were also read out by a researcher as they appeared on the PowerPoint presentations. Students could read the questions on the screen, or listen to them, or both. This measure was originally developed for New Zealand mathematics curriculum for Grades 1 - 8, and subsequently adapted for the Australian curriculum. Of note, based on age group, Grade 5 in New Zealand is equivalent to Grade 3 in Australia.

Attitudes towards mathematics: Participants' attitudes to Mathematics were measured using a modified (stage appropriate) version of the Programme for International Student Assessment (PISA) scales. This questionnaire has been validated by the Australian Council for Educational Research (ACER)(14). The 22-item questionnaire contained four separate subscales: i) confidence e.g., "How confident do you feel when adding two numbers in the hundreds" (8 items), ii) interest, e.g., "I really enjoy reading about mathematics" (4 items), iii) self-perception in mathematical skills, e.g., "I get good grades in maths" (4 items), and iv) negative thoughts, e.g., "I feel helpless when doing a mathematics problem" (6 items). The questions used a 4-point Likert scale ranging from 1 (strongly disagree) to 4 (strongly agree).

Executive function: Two measures of executive function (i.e., inhibition and working memory) were assessed using an online computer program: The Eriksen Flanker task was used to measure inhibition. The Flanker test is an interference task, in which different inputs compete with the target. Participants are asked to discriminate the arrows that have different direction. Congruent stimuli $(\rightarrow \rightarrow \rightarrow \rightarrow \rightarrow)$ elicit faster and more accurate responses, whereas incongruent stimuli $(\rightarrow \rightarrow \leftarrow \rightarrow \rightarrow)$ can reduce response speed and accuracy(15). Participants had to indicate the direction of the arrow in the middle as fast as they could. Their answers 
were recorded: the percentage number of correct answers (accuracy), the reaction time to complete the congruent tasks, as well as the time to complete the incongruent tasks (in seconds) were gauged. This task has been previously used in similar age group(16).

Working memory was measured using a version (2-back) of the "n-back task". Subjects monitored the identity or location of a series of nonverbal stimuli (i.e., pictures of ordinary objects such as cat or book) and indicated which presented stimulus are the same with the ones previously presented. The n-back working memory paradigm is a powerful tool measuring process and content-specific activation of working memory(17), commonly used in this age group(18). Participants' answers were recorded: The percentage of correct answers (accuracy) and the reaction time to complete the tasks (in seconds). The cognitive assessments lasted approximately 15 minutes per child at both time points.

\section{Statistical analysis}

Analyses of the outcomes were conducted using linear mixed models in IBM SPSS Statistics, version 23.0 (SPSS Inc., IBM Company Armonk, New York, United States). Mixed models were used to compare intervention effects and alpha levels were set at $p<0.05$. Mixed model analyses are consistent with the intervention-to-treat principle, assuming the data are missing at random(19). Little's missing completely at random test (MCAR(20)) was used to confirm this assumption (chi-square $(514)=485.10, p=0.815)$.

Linear mixed models were used to assess the impact of the group (activity breaks, activity breaks and mathematics combined or control), time (treated as categorical with levels baseline and 4-weeks), and the group-by-time interaction, using a random intercept to account for the repeated measures of each participant. Cohen's $d$ was also calculated and interpreted as follows: $d=0.2$, 'small' effect size, $d=0.5$, 'medium' effect size, and $d=0.8$, 'large' effect size(21). A summary of the outcome measures is demonstrated in Table 4 (at baseline, and 4weeks, adjusted mean differences and effect sizes).

\section{RESULTS}


On task behaviour: Significant group-by-time effects were observed for children's active engagement between the activity breaks and mathematics combined and control groups (adjusted mean difference $=44.1 \%, 95 \%$ Confidence Intervals $(\mathrm{Cl}) 28.1$ to $60.1, p<0.001$ ), between activity breaks and control groups (adjusted mean difference $=27.0 \%, 95 \% \mathrm{Cl}, 11.3$ to $42.7, p<0.001$ ), and between activity breaks and mathematics combined and activity breaks (adjusted mean difference $=17.1 \%, 95 \% \mathrm{Cl} 1.1$ to $33.1, p=0.037$ ). Significant group-by-time effects were also observed for children's passive engagement between the activity breaks and mathematics combined and control (adjusted mean difference $=-27.1 \%$, $95 \% \mathrm{Cl}-41.1$ to $-13.2, p<0.001)$, and between activity breaks and activity breaks and mathematics combined group (adjusted mean difference $=-19.3 \%, 95 \% \mathrm{Cl}-33.2$ to $-5.4, p=$ $0.008)$.

Academic achievement: Significant group-by-time effects were observed for mathematics scores between activity breaks and control (adjusted mean difference $=2.92$ units, $95 \% \mathrm{Cl}$, 0.07 to $5.77, p=0.045)$. Non-significant group-by-time effects were observed between activity breaks and mathematics combined and control group, and activity breaks and activity breaks and mathematics combined.

Executive function: Data were log transformed due to the non-normal distribution. No significant group-by-time effects were observed for children's inhibition as measured using the Flanker task or working memory using the n-back task.

Attitudes towards mathematics: Non-significant group-by-time effects were observed for children's confidence $(p=0.211)$, interest $(p=0.219)$, self-perceptions $(p=0.568)$, and negative thoughts $(p=0.533)$.

\section{DISCUSSION}

This study evaluated two different types of physical activity breaks, combined or without mathematics on primary school students' on-task behaviour, academic achievement and executive function. Consistent with our first hypothesis, children's on-task behaviour in the two physical activity conditions was improved. Specifically, the activity breaks and activity 
breaks and mathematics combined groups resulted in significant improvements in children's active engagement compared to the control group. Of note, the activity breaks and mathematics combined group was significantly higher than the activity breaks in increasing active engagement and it was the only condition with a significant decrease shown in passive engagement. The positive effects of five-minute activity breaks in on-task behaviour shown in this study are following the same direction with previous literature(22). However, in in this study, we did not find a decrease in off-task behaviour(23).

Significant group-by-time effects were found for Mathematics performance favouring the activity breaks compared to the control group, but not the activity breaks and mathematics combined group. Having an actual break from the academic instruction was actually beneficial for students for re-engaging their attention to the academic content. Previous research found no differences between active breaks and traditional seated lessons on mathematics performance(22), on-task behaviour, or sustained attention in primary school children(24). Possibly, longer activity breaks around 10 minutes or even physically active lessons, involving adjusted lessons with physical activities integrated with the academic instruction, would be able to fully engage students' to the academic curriculum, and enhance their on-task behaviour and academic performance(22, 25, 26).

In addition, further research is needed regarding the duration of physical activity breaks to enhance children's cognition. The total duration of the physical activity breaks (both activity breaks and activity breaks and mathematics combined) in this study was five minutes. Previous studies reported cognitive improvements observed when the physical activity breaks lasted 10 minutes or longer(27). However, none of the experimental conditions resulted in improvements in cognitive control (inhibition and working memory).

Cognitive control is important for academic achievement including school readiness and success, and physical and mental health(28). Even though existing literature confirm the positive effects of acute and repeated or chronic bouts of exercise on children's cognitive functioning(29), this was not the case in the current study. There are a number of potential explanations for these null findings. Most likely, the intensity and duration of physical activity breaks were not enough to elicit cognitive changes. The intensity levels were not measured, 
however, minimum moderate-to-vigorous physical activity would be required to produce effects. Regarding the 2 -n-back test, normative data showed that age is a strong predictor of the n-back task between children of 7-13 years(18). As such, this task could be considered as challenging for Grade 3 and 4 students.

Finally, there were no differences found in children's attitudes towards mathematics. It is probable that longer-term interventions are required to elicit changes in children's selfperceptions and attitudes regarding mathematics. It is important to note that the assessment of children's mathematical attitudes was preceded by their completion of the mathematics assessment task. Children's general thoughts and perceptions regarding mathematics may have been negatively influenced by their actual performance, as well as the perception of their performance in the mathematics test. Furthermore, students during the intervention received feedback for their answers but not during the testing. Possibly, a positive feedback would drive a more positive attitude towards maths and the reverse for the incorrect responses, influencing students' perceptions towards mathematics.

The main advantage of short classroom physical activity breaks lies on the fact that it requires minimal preparation by teachers, making it easily adjustable to the requirements of the crowded curriculum, and feasible to be applied even multiple times per day. As such, the physical activity breaks were conducted by the school teachers attributed higher ecologic validity to the study. However, limitations need to be acknowledged: this was a small-scale study and the generalisability of the results warrants concern. Also, this study, although it investigated the inclusion of physical activity during academic instruction, physical activity measurements were not included.

\section{CONCLUSION}

Overall, this study has further demonstrated the potential of physical activity breaks to improve on-task behaviour and academic achievement in children, which were proven to be more beneficial when they included mere physical activity rather than physical activity intermingled with academic content. This finding is particularly important considering that on- 
task behaviour can predict later academic success(6). Unlike many school-based physical activity interventions, activity breaks require minimal disruptions in lessons. As such, physical activity included in the daily instruction does not detract from academic performance, but it may actually enhance it(5). Physical activity breaks performed in the academic classrooms have gained amplified attention as a dynamic location for increasing children's physical activity. Additionally, classroom-based physical activity interventions are not negatively affecting students' learning, providing a strong counter-argument to some teachers' beliefs that increasing time spent in physical activity will adversely affect students' academic achievement(30). As a result, the academic classroom has the potential to be an integral component of a whole-of-school approach to physical activity that provides multiple health and learning benefits. 


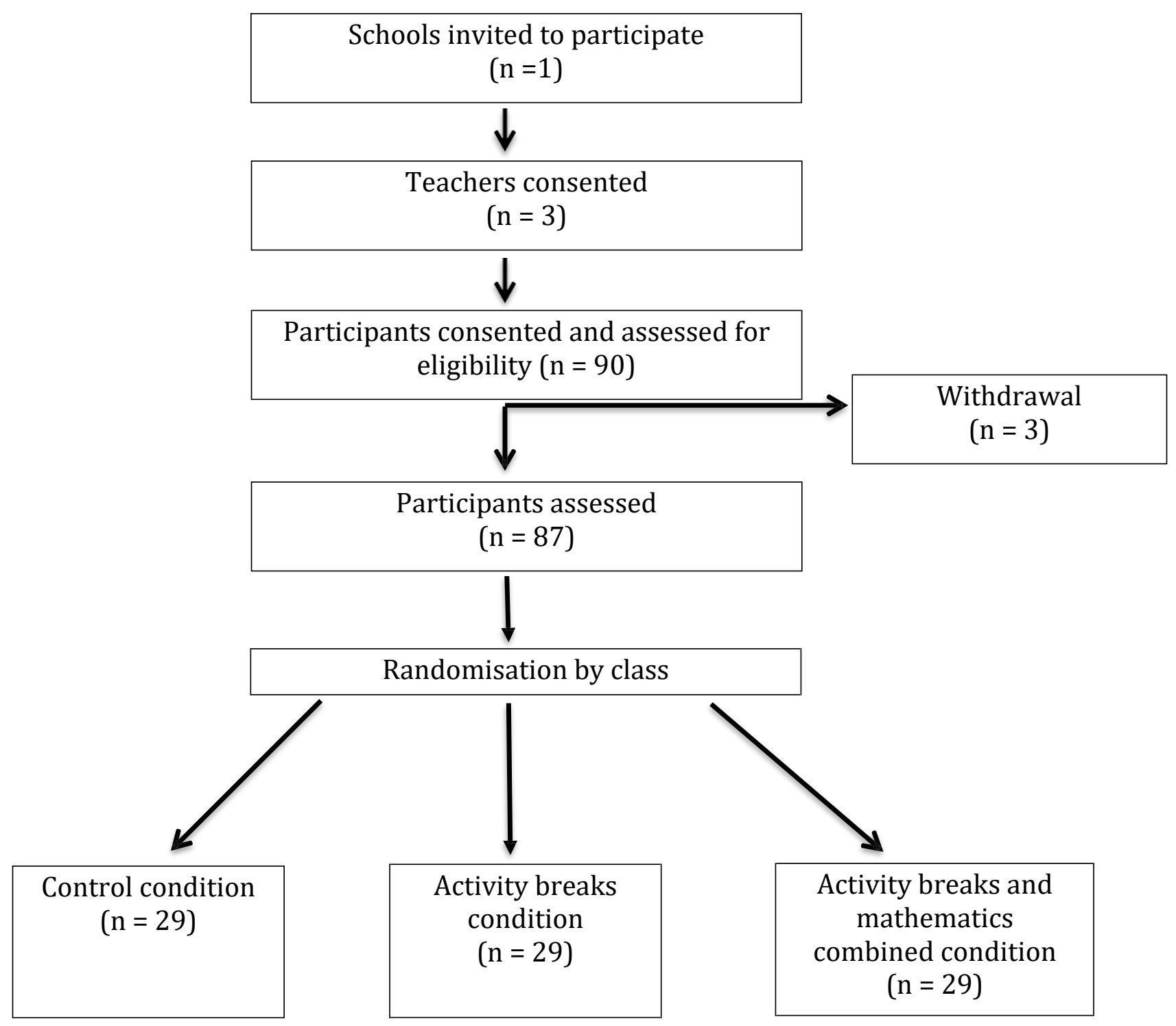

Figure 1. Flow chart of participants. 


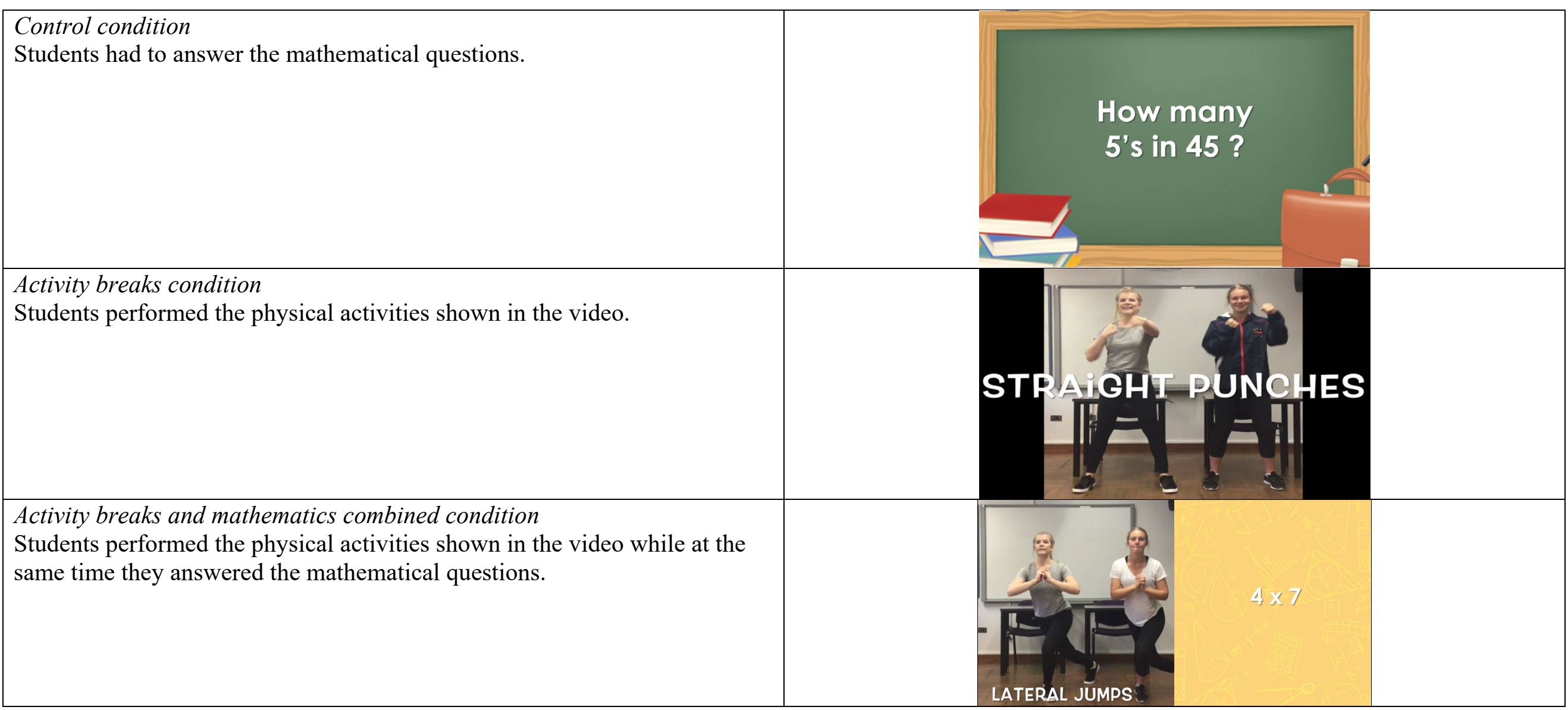

Figure 2. Summary of video content per condition. 
Table 1. Participant demographic characteristics.

\begin{tabular}{|c|c|c|c|c|}
\hline Characteristics & $\begin{array}{l}\text { Control } \\
(n=29)\end{array}$ & $\begin{array}{l}\text { AB } \\
(n=29)\end{array}$ & $\begin{array}{c}\text { ABM } \\
(n=29)\end{array}$ & $\begin{array}{c}\text { Total } \\
(n=87)\end{array}$ \\
\hline $\begin{array}{l}\text { Age (years), mean } \\
\text { (standard deviation) }\end{array}$ & $9.20(0.56)$ & $8.66(0.48)$ & $9.50(0.51)$ & $9.11(0.62)$ \\
\hline Grade 3 & $16(55.2)$ & $29(100)$ & $0(0)$ & $45(51.7)$ \\
\hline Grade 4 & $13(44.8)$ & $0(0)$ & $29(100)$ & $42(48.3)$ \\
\hline \multicolumn{5}{|l|}{ Sex, n (\%) } \\
\hline Male & $20(69)$ & $14(48.3)$ & $19(65.5)$ & $53(60.9)$ \\
\hline Female & $9(31)$ & $15(51.7)$ & $10(34.5)$ & $34(39.1)$ \\
\hline \multicolumn{5}{|l|}{$\begin{array}{l}\text { Cultural } \\
\text { background, n (\%) }\end{array}$} \\
\hline Australian & $28(96.6)$ & $29(100)$ & $28(96.6)$ & $85(97.7)$ \\
\hline Other & $1(3.4)$ & $0(0)$ & $1(3.4)$ & $2(2.3)$ \\
\hline \multicolumn{5}{|l|}{$\begin{array}{l}\text { Language spoken } \\
\text { at home, n (\%) }\end{array}$} \\
\hline English & $28(96.6)$ & $29(100)$ & $29(100)$ & $86(98.9)$ \\
\hline Other & $1(3.4)$ & $0(0)$ & $0(0)$ & $1(1.1)$ \\
\hline \multicolumn{5}{|l|}{$\begin{array}{l}\text { Aboriginal or } \\
\text { Torres Strait } \\
\text { Islander, n (\%) }\end{array}$} \\
\hline Yes & $3(10.3)$ & $2(6.9)$ & $4(13.8)$ & $9(10.3)$ \\
\hline No & $26(89.7)$ & $27(93.1)$ & $25(86.2)$ & $78(89.7)$ \\
\hline
\end{tabular}

Note, $\mathrm{AB}=$ activity break condition, $\mathrm{ABM}=$ activity break and mathematics combined condition 
Table 2. Summary of outcome measures.

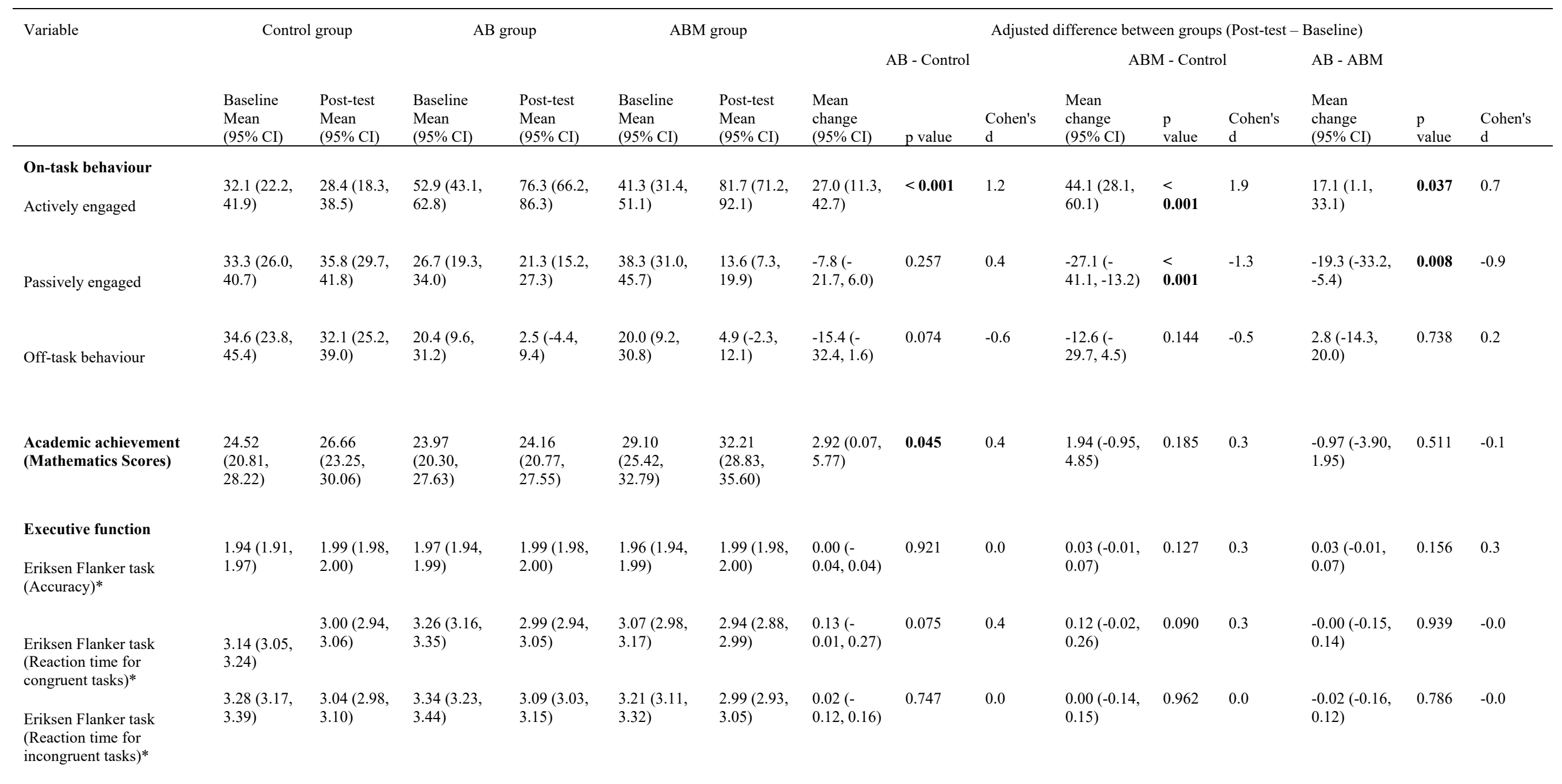




\begin{tabular}{|c|c|c|c|c|c|c|c|c|c|c|c|c|c|c|c|}
\hline 2-N back task (Accuracy) & $\begin{array}{l}35.25 \\
(30.59 \\
39.91)\end{array}$ & $\begin{array}{l}50.39 \\
(42.89 \\
57.89)\end{array}$ & $\begin{array}{l}29.39 \\
(24.80, \\
33.98)\end{array}$ & $\begin{array}{l}38.58 \\
(31.20 \\
45.95\end{array}$ & $\begin{array}{l}32.08 \\
(27.41, \\
36.74)\end{array}$ & $\begin{array}{l}45.70 \\
(38.44 \\
52.96)\end{array}$ & $\begin{array}{l}4.44(- \\
5.77, \\
14.65)\end{array}$ & 0.389 & 0.1 & $\begin{array}{l}5.95(-4.44, \\
16.34)\end{array}$ & 0.258 & 0.2 & $\begin{array}{l}1.51(-8.83 \\
11.85)\end{array}$ & 0.772 & 0.0 \\
\hline $\begin{array}{l}\text { 2-N back task (Reaction } \\
\text { time) }\end{array}$ & $\begin{array}{l}\text { 1106.82 (- } \\
5742.62, \\
7956.26)\end{array}$ & $\begin{array}{l}956.78 \\
(884.80, \\
1028.76)\end{array}$ & $\begin{array}{l}9349.89 \\
(2621.58, \\
16078.19)\end{array}$ & $\begin{array}{l}996.52 \\
(925.85, \\
1067.18)\end{array}$ & $\begin{array}{l}947.22(- \\
5902.19, \\
7796.64)\end{array}$ & $\begin{array}{l}1001.15 \\
(931.74, \\
1070.57)\end{array}$ & $\begin{array}{l}8407.30(- \\
1181.60, \\
17996.20)\end{array}$ & 0.085 & 0.3 & $\begin{array}{l}8203.32(- \\
1385.65, \\
17792.30)\end{array}$ & 0.093 & 0.3 & $\begin{array}{l}\text {-203.97 (- } \\
\text { 9878.31, } \\
9470.37)\end{array}$ & 0.967 & -0.0 \\
\hline \multicolumn{16}{|l|}{$\begin{array}{l}\text { Attitudes towards } \\
\text { mathematics }\end{array}$} \\
\hline Confidence & $\begin{array}{l}2.54(2.32 \\
2.77)\end{array}$ & $\begin{array}{l}2.64(2.41, \\
2.87)\end{array}$ & $\begin{array}{l}2.95(2.73, \\
3.17)\end{array}$ & $\begin{array}{l}2.84(2.62, \\
3.06)\end{array}$ & $\begin{array}{l}3.18(2.96, \\
3.40)\end{array}$ & $\begin{array}{l}3.11(2.88, \\
3.34)\end{array}$ & $\begin{array}{l}0.03(- \\
0.20,0.27)\end{array}$ & 0.775 & 0.0 & $\begin{array}{l}0.21(-0.04 \\
0.45)\end{array}$ & 0.097 & 0.3 & $\begin{array}{l}0.17(-0.07 \\
0.42)\end{array}$ & 0.169 & 0.3 \\
\hline Interest & $\begin{array}{l}2.82(2.51, \\
3.13)\end{array}$ & $\begin{array}{l}2.45(2.12 \\
2.78)\end{array}$ & $\begin{array}{l}3.11(2.81, \\
3.42)\end{array}$ & $\begin{array}{l}3.04(2.71 \\
3.36)\end{array}$ & $\begin{array}{l}2.67(2.36 \\
2.98)\end{array}$ & $\begin{array}{l}2.60(2.27 \\
2.92)\end{array}$ & $\begin{array}{l}-0.00(- \\
0.37,0.37)\end{array}$ & 0.994 & 0.0 & $\begin{array}{l}-0.29(- \\
0.67,0.08)\end{array}$ & 0.126 & -0.1 & $\begin{array}{l}-0.29(-0.67 \\
0.09)\end{array}$ & 0.130 & -0.2 \\
\hline Self-perception & $\begin{array}{l}2.63(2.36 \\
2.90)\end{array}$ & $\begin{array}{l}2.54(2.25 \\
2.82)\end{array}$ & $\begin{array}{l}2.76(2.49, \\
3.02)\end{array}$ & $\begin{array}{l}2.78(2.50 \\
3.06)\end{array}$ & $\begin{array}{l}2.55(2.29 \\
2.82)\end{array}$ & $\begin{array}{l}2.64(2.35 \\
2.92)\end{array}$ & $\begin{array}{l}0.06(- \\
0.26,0.39)\end{array}$ & 0.696 & -0.0 & $\begin{array}{l}-0.11(- \\
0.44,0.21)\end{array}$ & 0.498 & -0.3 & $\begin{array}{l}-0.17(-0.50, \\
0.15)\end{array}$ & 0.295 & -0.3 \\
\hline Negative thoughts & $\begin{array}{l}2.27(2.03 \\
2.51)\end{array}$ & $\begin{array}{l}2.15(1.86 \\
2.44)\end{array}$ & $\begin{array}{l}2.26(2.02 \\
2.49)\end{array}$ & $\begin{array}{l}2.11(1.82 \\
2.34)\end{array}$ & $\begin{array}{l}2.37(2.14 \\
2.61)\end{array}$ & $\begin{array}{l}2.09(1.80 \\
2.37)\end{array}$ & $\begin{array}{l}-0.13(- \\
0.44,0.18)\end{array}$ & 0.397 & -0.1 & $\begin{array}{l}0.04(-0.28 \\
0.36)\end{array}$ & 0.814 & 0.0 & $\begin{array}{l}0.17(-0.15 \\
0.49)\end{array}$ & 0.292 & 0.2 \\
\hline
\end{tabular}

* Log transformations

Note, $\mathrm{AB}=$ activity break condition, $\mathrm{ABM}=$ activity break and mathematics combined condition 


\section{References}

1. Janssen I, LeBlanc AG. Systematic review of the health benefits of physical activity and fitness in school-aged children and youth. Int J of Behav Nutr Phys Act 2010; 7 40:doi:10.1186/479-5868-7-40.

2. Lubans DR, Richards J, Hillman CH, Faulkner G, Beauchamp MR, Nilsson M, et al. Physical activity for cognitive and mental health in youth: A systematic review of mechanisms. Pediatrics 2016; 138 3:e20161642.

3. Álvarez-Bueno C, Pesce C, Cavero-Redondo I, Sánchez-López M, MartínezHortelano JA, Martínez-Vizcaíno $V$. The effect of physical activity interventions on children's cognition and metacognition: A systematic review and meta-analysis. J Am Acad of Child Adolesc Psychiatry. 2017; 56 9:729-38.

4. Hardy L, Mihrshahi S, Drayton B, Bauman A. NSW Schools Physical Activity and Nutrition Survey (SPANS). Full report. 2016 NSW Department of Health; 2017

5. Watson A, Timperio A, Brown H, Best K, Hesketh KD. Effect of classroom-based physical activity interventions on academic and physical activity outcomes: a systematic review and meta-analysis. Int J of Behav Nutr Phys Act. 2017; 14 1:114.

6. Mahar MT, Murphy SK, Rowe DA, Golden J, Shields AT, Raedeke TD. Effects of a classroom-based program on physical activity and on-task behavior. Med Sci Sports Exerc. 2006; 38 12:2086-94.

7. Schmidt M, Benzing V, Kamer M. Classroom-based physical activity breaks and children's attention: Cognitive engagement works! Front Psychol. 2016; 71474.

8. Eldridge SM, Lancaster GA, Campbell MJ, Thabane L, Hopewell S, Coleman CL, et al. Defining feasibility and pilot studies in preparation for randomised controlled trials: Development of a conceptual framework. PLOS ONE 2016; 11 3:e0150205.

9. Butte NF, Watson KB, Ridley K, Zakeri IF, McMurray RG, Pfeiffer KA, et al. A youth compendium of physical activities: Activity codes and metabolic intensities. Med Sci Sports Exerc. 2018; 50 2:246-56.

10. Alberto PA, Troutman AC. Applied behavior analysis for teachers. London, UK: Pearson Education, 2003.

11. Shapiro ES, Cole CL. Behavior change in the classroom: Self-management interventions. New York, NY, USA: Guilford Press, 1994.

12. Riley N, Lubans DR, Holmes K, Morgan PJ. Rationale and study protocol of the EASY Minds (Encouraging Activity to Stimulate Young Minds) program: Cluster randomized controlled trial of a primary school-based physical activity integration program for mathematics. BMC Public Health 2014; 14 819:10.1186/471-2458-14816.

13. Tait-McCutceon S, Drake M. The individual basic facts assessment tool. In: Marshman M, Geiger V, Bennison A, editors. Mathematics education in the margins. Sunshine Coast: MERGA: Proceedings of the 38th annual conference of the Mathematics Education Research Group of Australasia; 2015

14. Thompson S, Hillman K, De Bortoli L. A teacher's guide to PISA mathematical literacy. Camberwell, Victoria, Australia: Australian Council for Educational Research (ACER), 2013.

15. Hillman $\mathrm{CH}$, Snook EM, Jerome GJ. Acute cardiovascular exercise and executive control function. I J Psychophysiol. 2003; 48 3:307-14.

16. Scudder MR, Lambourne K, Drollette ES, Herrmann SD, Washburn RA, Donnelly JE, et al. Aerobic capacity and cognitive control in elementary school-age children. Med Sci Sports Exerc. 2014; 46 5:1025-35.

17. Owen AM, McMillan KM, Laird AR, Bullmore E. N-back working memory paradigm: A meta-analysis of normative functional neuroimaging studies. Hum Brain Mapp. 2005; 25 1:46-59.

18. Pelegrina S, Lechuga MT, García-Madruga JA, Elosúa MR, Macizo P, Carreiras M, et al. Normative data on the n-back task for children and young adolescents. Front Psychol. 2015; 61544.

19. White IR, Carpenter J, Horton NJ. Including all individuals is not enough: Lessons for intention-to-treat analysis. Clin. Trials 2012; 9 4:396-407. 
20. Little RJA, Rubin DB. Bayes and multiple imputation. Statistical Analysis with Missing Data: Wiley Series in Probability and Statistics, 2014.

21. Vacha-Haase $T$, Thompson B. How to estimate and interpret various effect sizes. $J$ Counsel Psychol 2004; 51 4:473-81.

22. Watson AJL, Timperio A, Brown H, Hesketh KD. A pilot primary school active break program (ACTI-BREAK): Effects on academic and physical activity outcomes for students in Years 3 and 4. J Sci Med Sport 2018.

23. Ma JK, Mare LL, Gurd BJ. Classroom-based high-intensity interval activity improves off-task behaviour in primary school students. Appl Physiol Nutr Metab. 2014; 39 12:1332-7.

24. Wilson AN, Olds T, Lushington K, Petkov J, Dollman J. The impact of 10-minute activity breaks outside the classroom on male students' on-task behaviour and sustained attention: a randomised crossover design. Acta Paediatr. 2016; 105 4:e181-e8.

25. Mavilidi MF, Ruiter M, Schmidt M, Okely AD, Loyens S, Chandler P, et al. A narrative review of school-based physical activity for enhancing cognition and learning: The importance of relevancy and integration. Front Psychol. 2018; 9.

26. Mavilidi MF, Okely A, Chandler P, Domazet S L, Paas F. Immediate and delayed effects of integrating physical activity into preschool children's learning of numeracy skills. J Exp Child Psychol. 2018; 166:502-19.

27. Chang YK, Labban JD, Gapin JI, Etnier JL. The effects of acute exercise on cognitive performance: a meta-analysis. Brain Res 2012; 1453:87-101.

28. Diamond A, Lee K. Interventions shown to aid executive function development in children 4 to 12 years old. Science 2011; 333 6045:959-64.

29. Hillman $\mathrm{CH}$, Erickson $\mathrm{KI}$, Kramer AF. Be smart, exercise your heart: exercise effects on brain and cognition. Nat Rev Neurosci. 2008; 9 1:58-65.

30. Naylor P, Nettlefold L, Race D, Hoy C, Ashe MC, Higgins JW, et al. Implementation of school based physical activity interventions: A systematic review. Prev Med 2015; 72:95-115. 
